\title{
Detection of cerebral hypoperfusion with a dynamic hyperoxia test using brain oxygenation pressure monitoring
}

\author{
Thomas Gargadennec ${ }^{1,2+}$, Gioconda Ferraro ${ }^{1 \dagger}$, Rudy Chapusette ${ }^{3}$, Xavier Chapalain ${ }^{1,2}$, Elisa Bogossian? , \\ Morgane Van Wettere ${ }^{3}$, Lorenzo Peluso ${ }^{1}$, Jacques Creteur ${ }^{1}$, Olivier Huet ${ }^{2}$, Niloufar Sadeghi ${ }^{3}$ and \\ Fabio Silvio Taccone 1* $^{*}$
}

\begin{abstract}
Introduction: Brain multimodal monitoring including intracranial pressure (ICP) and brain tissue oxygen pressure $\left(\mathrm{PbtO}_{2}\right)$ is more accurate than ICP alone in detecting cerebral hypoperfusion after traumatic brain injury (TBI). No data are available for the predictive role of a dynamic hyperoxia test in brain-injured patients from diverse etiology.

Aim: To examine the accuracy of $\mathrm{ICP}, \mathrm{PbtO}_{2}$ and the oxygen ratio (OxR) in detecting regional cerebral hypoperfusion, assessed using perfusion cerebral computed tomography (CTP) in patients with acute brain injury.

Methods: Single-center study including patients with TBI, subarachnoid hemorrhage (SAH) and intracranial hemorrhage (ICH) undergoing cerebral blood flow (CBF) measurements using CTP, concomitantly to ICP and $\mathrm{PbtO}_{2}$ monitoring. Before CTP, $\mathrm{FiO}_{2}$ was increased directly from baseline to $100 \%$ for a period of 20 min under stable conditions to test the $\mathrm{PbtO}_{2}$ catheter, as a standard of care. Cerebral monitoring data were recorded and samples were taken, allowing the measurement of arterial oxygen pressure $\left(\mathrm{PaO}_{2}\right)$ and $\mathrm{PbtO}_{2}$ at $\mathrm{FiO}_{2} 100 \%$ as well as calculation of OxR $\left(=\triangle \mathrm{PbtO}_{2} / \triangle \mathrm{PaO}_{2}\right)$. Regional CBF (rCBF) was measured using CTP in the tissue area around intracranial monitoring by an independent radiologist, who was blind to the $\mathrm{PbtO}_{2}$ values. The accuracy of different monitoring tools to predict cerebral hypoperfusion (i.e., $\mathrm{CBF}<35 \mathrm{~mL} / 100 \mathrm{~g} \times \mathrm{min}$ ) was assessed using area under the receiver-operating characteristic curves (AUCS).
\end{abstract}

Results: Eighty-seven CTPs were performed in 53 patients (median age 52 [41-63] years-TBI, $n=17 ; \mathrm{SAH}, n=29$; $\mathrm{ICH}, n=7$ ). Cerebral hypoperfusion was observed in 56 (64\%) CTPs: ICP, $\mathrm{PbtO}_{2}$ and OxR were significantly different between CTP with and without hypoperfusion. Also, rCBF was correlated with ICP $(r=-0.27 ; p=0.01), \mathrm{PbtO}_{2}$ $(r=0.36 ; p<0.01)$ and $\mathrm{OxR}(r=0.57 ; p<0.01)$. Compared with ICP alone (AUC $=0.65[95 \% \mathrm{Cl}, 0.53-0.76])$, monitoring $\mathrm{ICP}+\mathrm{PbO}_{2}(\mathrm{AUC}=0.78[0.68-0.87])$ or ICP $+\mathrm{PbtO}_{2}+\mathrm{OxR}(\mathrm{AUC}=0.80(0.70-0.91)$ was significantly more accurate in predicting cerebral hypoperfusion. The accuracy was not significantly different among different etiologies of brain injury.

\footnotetext{
*Correspondence: fabio.taccone@ulb.be

†Thomas Gargadennec and Gioconda Ferraro have contributed equally to this work as first author

${ }^{1}$ Department of Intensive Care, Hospital Erasme, Université Libre de Bruxelles (ULB), Route de Lennik, 808, 1070 Brussels, Belgium

Full list of author information is available at the end of the article
}

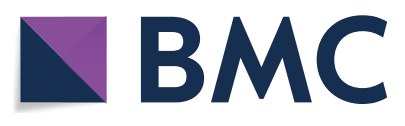

(c) The Author(s) 2022. Open Access This article is licensed under a Creative Commons Attribution 4.0 International License, which permits use, sharing, adaptation, distribution and reproduction in any medium or format, as long as you give appropriate credit to the original author(s) and the source, provide a link to the Creative Commons licence, and indicate if changes were made. The images or other third party material in this article are included in the article's Creative Commons licence, unless indicated otherwise in a credit line to the material. If material is not included in the article's Creative Commons licence and your intended use is not permitted by statutory regulation or exceeds the permitted use, you will need to obtain permission directly from the copyright holder. To view a copy of this licence, visit http://creativecommons.org/licenses/by/4.0/. The Creative Commons Public Domain Dedication waiver (http://creativeco mmons.org/publicdomain/zero/1.0/) applies to the data made available in this article, unless otherwise stated in a credit line to the data. 
Conclusions: The combination of $\mathrm{ICP}$ and $\mathrm{PbtO}_{2}$ monitoring provides a better detection of cerebral hypoperfusion than ICP alone in patients with acute brain injury. The use of dynamic hyperoxia test could not significantly increase the diagnostic accuracy.

Keywords: Brain injury, Oxygen test, Hypoperfusion, Multimodal monitoring

\section{Introduction}

Acute severe brain injury, either secondary to trauma or non-traumatic events, is still associated with a significant burden of long-term neurological sequelae $[1,2]$ and represents one of the major causes of morbidity and mortality in previously healthy population [3]. On the opposite to the initial brain injury, whose severity can be barely modified, secondary brain injuries (SBIs) could be detected and potentially avoidable. Those SBI, including either cerebral (i.e., brain edema, tissue hypoxia, seizures) or systemic (i.e., hypotension, hypocapnia, hypoxemia, dysglycemia, hyponatremia, fever and anemia) events, can enhance the extent of the primary brain insult and further contribute to poor outcome in this setting [4-7].

Following the occurrence of SBI, cerebral blood flow (CBF) might become inadequate to provide sufficient oxygen and nutrients supply to meet the metabolic needs of the injured brain [8]. Imaging techniques can provide relevant information on CBF alterations after acute brain injury; in particular, cerebral computed tomography perfusion (CTP) imaging, which was initially introduced to estimate the infarct core size and evaluate the time window for thrombolysis and thrombectomy in ischemic stroke [9], can detect perfusion deficits associated with cerebral vasospasm, which might occur in patients suffering from subarachnoid hemorrhage (SAH), or reduced $\mathrm{CBF}$ around contusion areas and cerebral perfusion heterogeneity in the early phase of TBI $[10,11]$. However, CTP is not a bedside tool, does not provide continuous CBF measurement and can be associated with some adverse events, such as high-dose radiation exposure and an increased risk of elevated intracranial pressure (ICP) during the in-hospital transfer to the radiology unit [12].

As such, alternative monitoring tools are available to estimate the occurrence of brain hypoperfusion at the bedside. Among them, ICP and cerebral perfusion pressure (CPP) monitoring are widely recommended, in particular for TBI patients, to identify patients at risk of brain hypoperfusion. Nevertheless, CBF might be inadequate even in the absence of abnormal ICP/CPP values [13]; as such, invasive brain tissue oxygenation $\left(\mathrm{PbtO}_{2}\right)$ monitoring could provide additional information on the equilibrium between oxygen delivery, diffusion and consumption within the brain parenchyma and detect the occurrence of tissue hypoxia even in the absence of elevated ICP [14]. In one study, the combination of
ICP and $\mathrm{PbtO}_{2}$ monitoring was more accurate than ICP monitoring alone in detecting cerebral hypoperfusion in TBI patients [15]. However, this study included only 30 CTPs and focused only on TBI with predominantly diffuse injury, which would limit the generalizability of these findings to a larger cohort of brain-injured patients. Moreover, $\mathrm{PbtO}_{2}$ cannot directly reflect $\mathrm{CBF}$ values, as brain oxygenation is also influenced by other factors, such as hemoglobin values, brain temperature, microvascular impairment and arterial oxygenation [16]. Changes in arterial oxygen pressure $\left(\mathrm{PaO}_{2}\right)$ could result in concomitant changes in $\mathrm{PbtO}_{2}$, whose magnitude is dependent from local regulatory mechanisms, brain metabolism as well as the adequacy of regional perfusion. As such, one may argue that a challenge of increased arterial oxygenation could provide a more significant increase in $\mathrm{PbtO}_{2}$ in those area with sufficient vascular supply, while the tissue oxygen response would be more limited in hypoperfused areas. In one study, van Santibrink et al. showed that increased tissue oxygen response was associated with poor prognosis in TBI patients [17]; however, no data on the association of such response with regional perfusion were provided.

Therefore, the aim of this study was to assess the role of a dynamic oxygen challenge to identify cerebral hypoperfusion in brain-injured patients. We hypothesized that a higher tissue oxygen response could correlate with increased regional CBF values in these patients.

\section{Methods \\ Study population}

This was an analysis of prospectively collected data including all adult ( $>18$ years of age) patients with an acute primary brain injury (i.e., TBI, SAH or intracranial hemorrhage, ICH) admitted to the ICU of Erasme Hospital, Brussels, Belgium, between January 2016 and August 2019. Eligible patients were those: (a) having a $\mathrm{PbtO}_{2}$ monitoring catheter, which was inserted according to the decision of senior ICU physician and an experienced neurosurgeon; (b) underwent daily dynamic oxygen challenge (see below) as part of routine assessment of $\mathrm{PbtO}_{2}$ function; (c) underwent a CTP within $3 \mathrm{~h}$ from the dynamic oxygen challenge. Data for all measurements were recorded into the patient management data system (PDMS, Picis Critical Care Manager, Picis Inc., Wakefield, USA). Exclusion criteria were a malfunctioning $\mathrm{PbtO}_{2}$ 
catheter, the lack of data on the dynamic oxygen challenge, poor-quality CTP images (i.e., inadequate contrast medium injection and/or artifacts), baseline-inspired oxygen fraction $\left(\mathrm{FiO}_{2}\right)$ on the ventilator $\geq 80 \%$ and the use of prone positioning and/or extra-corporeal membrane oxygenation. The study was approved by the ethical committee of the Erasme Hospital (Comité d'Ethique Hospitalo-Facultaire Erasme-ULB; P2021/348), which waived the need of informed consent given the observational design of the study analyzing recorded data into the PDMS.

\section{Patients' management and dynamic oxygen challenge}

Patients were managed according to local protocols, based on international recommendations [18-20]. A triple lumen bolt allowing the insertion of a $\mathrm{PbtO}_{2}$ probe (IM3.ST_EU, Integra LifeSciences Corporation, Plainsboro, NJ, USA), alone or in association with an 8-contact depth EEG electrode and a microdialysis catheter, was placed in the operating room by a neurosurgeon in patients with TBI, SAH or ICH, who had indications for ICP monitoring (i.e., abnormal CT-scan findings and a Glasgow Coma Score on admission $<9$ ). The bolt was positioned in the normal-appearing brain area of the injured side (TBI or ICH) or, in case of aneurysmal SAH, on either the ipsilateral side of the aneurysm (i.e., anterior circulation) or on the right side (i.e., no aneurysm identified or aneurysm located in the posterior circulation). Other continuously monitored variables included heart rate, mean arterial pressure (MAP), peripheral oxygen saturation, end-tidal carbon dioxide and body temperature (i.e., with urinary or esophageal probes), ICP and CPP; CPP was calculated as the difference between MAP and ICP; MAP was zeroed at the level of the left atrium. ICP and CPP targets were $<20$ and $>60 \mathrm{mmHg}$, respectively.

After the initial daily assessment of the patient including arterial blood gas analyses (ABG), a dynamic oxygen challenge, i.e., increasing of $\mathrm{FiO}_{2}$ to $100 \%$ for $20 \mathrm{~min}$, was performed and another $A B G$ repeated at the end of this period. As such, $\mathrm{PaO}_{2}$ and $\mathrm{PbtO}_{2}$ were measured at baseline and after the dynamic oxygen challenge. This dynamic challenge was part of the routine management of patients and performed by an experienced intensivist (FST), whenever possible. Apart from the dynamic oxygen challenge, all other relevant physiological variables were kept stable. The oxygen ratio (OxR) was then calculated as follows: $\mathrm{OxR}=\left(\mathrm{PbtO}_{2}\right.$ at $\mathrm{FiO}_{2} 100 \%-\mathrm{PbtO}_{2}$ at baseline $) /\left(\mathrm{PaO}_{2}\right.$ at $\mathrm{FiO}_{2} 100 \%-\mathrm{PaO}_{2}$ at baseline $)$.

\section{Data collection}

For all patients, demographics, comorbid diseases, reasons for ICU admission as well as ICU length of stay and hospital mortality were collected. The severity of disease scores (i.e., Glasgow Coma Scale on admission, World Federation of Neurological Surgeons-WFNS-score in SAH patients, Marshall and modified Fisher scores for cerebral CT-scan in TBI or SAH patients, respectively, location and volume of $\mathrm{ICH}$ ) was collected. Intracranial hypertension was defined by the ICP value above $20 \mathrm{mmHg}$ immediately before the dynamic challenge test; also, brain tissue hypoxia was defined by a $\mathrm{PbtO}_{2}$ below $20 \mathrm{mmHg}$ at the same moment.

Neurological outcome at hospital discharge was assessed using the Glasgow Outcome Scale (GOS); favorable neurological outcome (FO) was considered as a GOS 4-5, while unfavorable outcome (UO) as GOS 1-3.

\section{Cerebral CT perfusion scan}

Cerebral CTP was performed using a multidetector row CT (FORCE Dual Energy, Siemens Healthcare, Erlangen, Germany) and considered the reference method to identify areas of cerebral hypoperfusion. The indication for CTP was based on the decision of the attending ICU physician after discussion with a senior radiologist and, in general, based on the suspicion of cerebral vasospasm (SAH) or to assess the extension of cerebral hypoperfusion (TBI, ICH); the decision to perform CTP was independent from the results of the dynamic hyperoxia test. All available CTPs paired by a dynamic oxygen challenge were considered for the final analysis. The method of acquisition was similar to what previously described by Bouzat et al. [15]; scanning was initiated $5 \mathrm{~s}$ after injection of $50 \mathrm{~mL}$ of iohexol $(300 \mathrm{mg} / \mathrm{mL}$ of iodine; GE Healthcare, Milwaukee, WI), at a rate of $5 \mathrm{~mL} / \mathrm{s}$, with the following variables: $80 \mathrm{kV}, 240 \mathrm{mAs}, 0.4$ rotations $/ \mathrm{s}$, and total duration of $50 \mathrm{~s}$. The series evaluated 16 adjacent 5 -mm-thick sections of brain parenchyma. Post-processing of CTP data was performed by two experienced neuroradiologists, using a dedicated software (Brilliance Workspace Portal; Philips Medical Systems, Cleveland, $\mathrm{OH}$ ), focusing on one region of interest (ROI), which was manually drawn around the probe (surface area, $\sim 50 \mathrm{~mm}^{2}$ ) to calculate regional CBF (Fig. 1). Assessment of regional CBF was performed blindly to ICP and $\mathrm{PbtO}_{2}$ data. Low regional cerebral blood flow (rCBF) was defined by a value below $35 \mathrm{~mL} / 100 \mathrm{~g} \times \min$ [15]

\section{Study outcomes}

The primary outcome of the study was to compare the accuracy of ICP, $\mathrm{PbtO}_{2}$ or OxR and their combinations to detect cerebral hypoperfusion in brain-injured patients. Secondary outcomes included: (a) the accuracy to detect cerebral hypoperfusion of all these variables according to the underlying brain disease. 


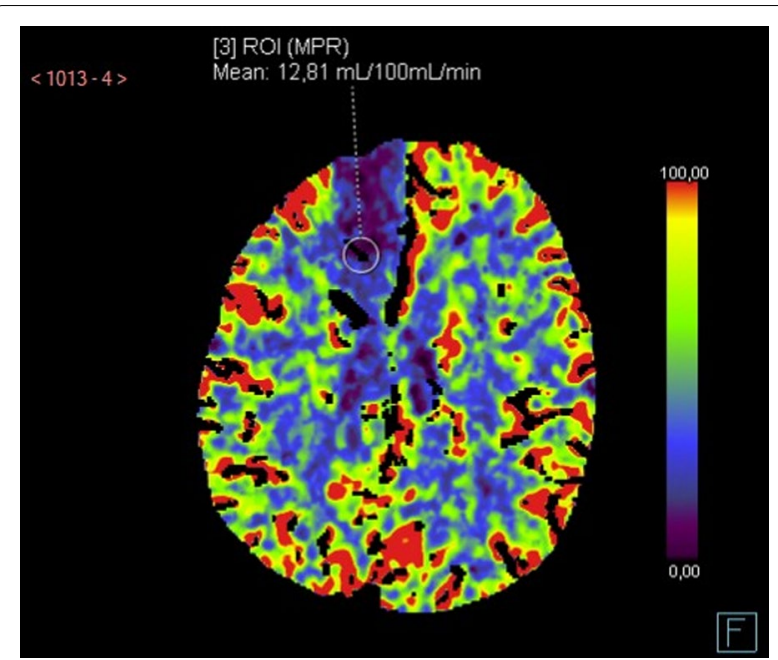

Fig. 1 Patient with severe subarachnoid hemorrhage, who underwent a cerebral CT-perfusion (CTP) on day 2. White circle indicated the region of interest (ROI) for CTP analysis of regional cerebral blood flow (rCBF); rCBF was estimated at $12.8 \mathrm{~mL} / 100 \mathrm{~g}$ $\times$ min, while intracranial pressure and cerebral perfusion pressure were $16 \mathrm{mmHg}$ and $73 \mathrm{mmHg}$, respectively, and baseline $\mathrm{PbtO}_{2}$ was $22 \mathrm{mmHg}$ (for a $\mathrm{PaO}_{2}$ of $119 \mathrm{mmHg}$ ). Measured OxR was 0.14

\section{Statistical analysis}

Data were analyzed using $\mathrm{R}$ statistical software version 4.0.3 (R Foundation for Statistical Computing), Prism (GraphPad Software Inc.) and IBM SPSS Statistics for Macintosh 27 (Armonk, NY, USA). Categorical variables were expressed as count (percentage) and continuous variables as mean \pm standard deviation (SD) or median [25th-75th percentiles]. The Kolmogorov-Smirnov test was used, and histograms and normal-quantile plots were examined to verify the normality of distribution of continuous variables. Differences between groups were assessed using the Chi-square test or Fisher's exact test for categorical variables and Student's t-test, or Mann-Whitney U-test for continuous variables, as appropriate. The discriminative ability of each variable or combination to predict cerebral hypoperfusion was evaluated using receiver operating characteristic (ROC) curves with the corresponding area under the curve (AUROC), and sensitivity, specificity, positive (PPV) and negative predictive value (NPV) were computed. For each variable, the optimal predictive threshold was calculated using the Youden's index. Differences between AUROCs were assessed using the DeLong analysis. Correlations between monitoring variables and CTP data were measured with Pearson's correlation coefficient. All tests were two-tailed, and statistical significance was set at the $5 \%$ level.
Table 1 Characteristics of the study population. Data are presented as count (\%) or median [IQRs]

\begin{tabular}{|c|c|}
\hline & $n=53$ \\
\hline Age, years & $52[41-63]$ \\
\hline Female/male ratio & $25 / 28$ \\
\hline GCS on admission & $9[5-14]$ \\
\hline Subarachnoid hemorrhage & 29 \\
\hline \multicolumn{2}{|l|}{ Fisher classification } \\
\hline 3 & 7 \\
\hline 4 & 22 \\
\hline \multicolumn{2}{|l|}{ WFNS classification } \\
\hline 1 & 5 \\
\hline 2 & 4 \\
\hline 3 & 0 \\
\hline 4 & 7 \\
\hline 5 & 13 \\
\hline Traumatic brain injury & 17 \\
\hline \multicolumn{2}{|l|}{ Marshall classification } \\
\hline 3 & 4 \\
\hline 4 & 6 \\
\hline 5 & 2 \\
\hline 6 & 5 \\
\hline Intracerebral hemorrhage & 7 \\
\hline Hematoma $>30 \mathrm{~mL}$ & 6 \\
\hline GOS at hospital discharge & $3[1-3]$ \\
\hline 30-day mortality & $15(28)$ \\
\hline ICU length of stay, days & 21 [15-29] \\
\hline
\end{tabular}

GCS Glasgow Coma Scale, WFNS World Federation of Neurosurgical Societies, GOS Glasgow Outcome Scale, ICU intensive care unit

\section{Results}

\section{Study population}

Over the study period, 123 patients underwent $\mathrm{PbtO}_{2}$ monitoring; of those, $70(n=43$, no CTP; $n=4$, poorquality imaging; $n=9$ with $\mathrm{FiO}_{2}>80 \% ; n=14$, no dynamic challenge test-Additional file 1: Fig. S1) were excluded leaving 53 patients for the final analysis. Characteristics of the study population are shown in Table 1 ; median age was 52 [41-63] years; and $25(44 \%)$ were female. Admission diagnosis was SAH in 29 (51\%), TBI in $17(30 \%)$ and $\mathrm{ICH}$ in 7 (12\%) patients. Overall mortality was $28 \%$; median GOS at hospital discharge was 3 [1-3].

\section{Cerebral CT perfusion}

A total of 87 CTPs were performed; one patient had 6 examinations, two underwent 4 CTPs, one patient 3 CTPs, twenty-one 2 CTPs and the 28 remaining patients one CTP; 56 (64\%) CTPs were performed in SAH, 20 (23\%) in TBI and 11 (13\%) in ICH patients. The median time between the insertion of $\mathrm{PbtO}_{2}$ catheter and CTP was 6 [3-9] days; no correlation between the time to 
insertion of the catheter and baseline $\mathrm{PbtO}_{2}(r=0.001$; $p=0.97)$ and $\mathrm{PbtO}_{2}$ at $\mathrm{FiO}_{2}$ of $100 \%(r=-0.13 ; p=0.24)$ was observed.

\section{Brain hypoperfusion and dynamic oxygen test}

Fifty-six (64\%) CTPs were associated with regional cerebral hypoperfusion; CTPs showing cerebral hypoperfusion had higher ICP, lower $\mathrm{PbtO}_{2}$ at baseline and at $\mathrm{FiO}_{2}$ of $100 \%$ and lower OxR (Fig. 2) when compared to others; however, no differences in $\mathrm{CPP}, \mathrm{PaO}_{2}$, hemoglobin and $\mathrm{PaCO}_{2}$ were observed between the two groups (Table 2).

The OxR had the highest correlation with regional CBF $(r=0.57 ; p<0.001)$, when compared to ICP $(r=-0.35$; $p=0.01)$ and $\mathrm{PbtO}_{2}$ at baseline $(r=0.36 ; p=0.006-$ Fig. 3). An ICP $>20 \mathrm{mmHg}$ had a specificity of $21 \%$ and a sensitivity of $97 \%$ to detect brain hypoperfusion, while a $\mathrm{PbtO}_{2}<20 \mathrm{mmHg}$ had a specificity of $62 \%$ and a sensitivity of $84 \%$ to detect brain hypoperfusion. An OxR $<0.20$ had a $48 \%$ specificity and $81 \%$ sensitivity to detect brain hypoperfusion.

Intracranial hypertension was present in $13(25 \%)$ of CTPs; of those, 12 (92\%) had brain hypoperfusion; among the 74 CTPs without intracranial hypertension, $44(60 \%)$ had brain hypoperfusion (Additional file 1: Fig. S2). Brain hypoxia was present in 30 (58\%) CTPs; of those, 26 (87\%) had brain hypoperfusion; among the 57 CTPs without brain hypoxia, 30 (52\%) had brain hypoperfusion. A total of 23/56 (41\%) with CTPs showing brain hypoperfusion had neither intracranial hypertension nor tissue hypoxia (Additional file 1: Table S1). Low OxR

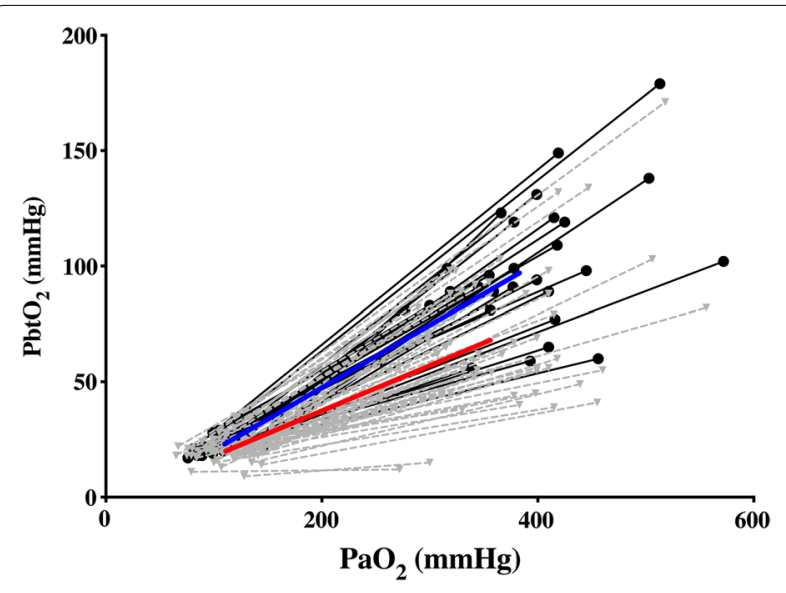

Fig. 2 Representation of brain tissue oxygen pressure $\left(\mathrm{PbtO}_{2}\right)$ and arterial blood partial pressure of oxygen $\left(\mathrm{PaO}_{2}\right)$ during hyperoxia test at $\mathrm{FiO}_{2}, 100 \%$. Each test is represented by two points united by one straight line. Depending on regional cerebral blood flow ( $\mathrm{rCBF}$ ) points and lines are black full circles united by black lines (normal rCBF) or grey triangles united by grey dotted lines (oligemia, i.e., regional cerebral blood flow $<35 \mathrm{~mL} / 100 \mathrm{~g} \times \mathrm{min}$ ). The blue line unit means of $\mathrm{PbtO}_{2}$ and $\mathrm{PbtO}_{2}$ at $\mathrm{FiO}_{2}$ 100\% in the group with normal rCBF and the red line units means in the group with oligemia (i.e., <0.20) was present in 33 (38\%) of CTPs; of those, 27 (81\%) had brain hypoperfusion; among the 54 CTPs without low OxR, 29 (54\%) had brain hypoperfusion. A total of 11 out of 23 CTPs with brain hypoperfusion showed only low OxR, without intracranial hypertension or tissue hypoxia (Additional file 1: Fig. S2). While the combination of at least two abnormal parameters between ICP $(>20 \mathrm{mmHg}), \mathrm{PbtO}_{2}(<20 \mathrm{mmHg})$ and $\mathrm{OxR}(<0.20)$ resulted in brain hypoperfusion on CTP in $82-100 \%$ of cases, the absence of at least of these two abnormal values was associated with brain hypoperfusion in $39-47 \%$ of cases (Additional file 1: Figs. S2 and S3).

\section{Predictors of brain hypoperfusion}

As reported in Table 3 and Fig. 2, the most accurate variables to detect brain hypoperfusion were $\mathrm{PbtO}_{2}$ at baseline and OxR. Different combinations of neuromonitoring data (i.e., ICP with $\mathrm{PbtO}_{2}$; ICP with OxR; ICP with $\mathrm{PbtO}_{2}$ and $\mathrm{OxR}$ ) resulted in significantly higher AUC than ICP alone $(p=0.01, p=0.04$ and $p=0.02$ vs. ICP, respectively); the combination of ICP and $\mathrm{PbtO}_{2}$ yielded similar results than the combination of ICP, $\mathrm{PbtO}_{2}$ and OxR.

\section{Subgroup analyses}

Differences in main characteristics between patients with and without hypoperfusion on CTP, according to the presence of a traumatic $(n=19)$ or non-traumatic $(n=68)$ brain injury, are reported in Additional file 1: Tables S2 and S3. Correlations of ICP, $\mathrm{PbtO}_{2}$ and $\mathrm{OxR}$ with $\mathrm{rCBF}$ are reported, according to the presence of a traumatic or non-traumatic brain injury, in Additional file 1: Tables S4 and S5; results were similar to those of the entire cohort. In CTP associated with TBI $(n=19)$, the highest AUC to predict brain hypoperfusion was observed for the combination of ICP, $\mathrm{PbtO}_{2}$ at baseline and OxR (0.90 [0.75-1.00]), although it was not significantly different than ICP and $\mathrm{PbtO}_{2}$ or ICP and OxR (Additional file 1: Table S4). In CTP with non-traumatic brain injury $(n=68)$, the highest AUC to predict brain hypoperfusion was observed for the combination of ICP, $\mathrm{PbtO}_{2}$ at baseline and $\mathrm{OxR}(0.79$ [0.69-0.90]), which was significantly better than ICP alone $(p=0.01)$ but not significantly different than ICP and $\mathrm{PbtO}_{2}$ or ICP and OxR (Additional file 1: Table S5).

\section{Discussion}

In this retrospective observational study, we observed that a multimodal evaluation including ICP and $\mathrm{PbtO}_{2}$ could more accurately detect brain hypoperfusion in a heterogeneous population of brain-injured patients. The dynamic hyperoxia test, which allowed to compute the OxR, did not significantly improve the diagnostic 
Table 2 Differences in main available data on the day of cerebral CT perfusion (CTP), according to the presence of brain hypoperfusion (i.e., regional cerebral blood flow $<35 \mathrm{~mL} / 100 \mathrm{~g} \times \mathrm{min}$ ). Data are presented as count (\%) or median [IQRs]

\begin{tabular}{|c|c|c|c|c|}
\hline & ALL $(n=87)$ & Brain hypoperfusion $(n=56)$ & $\begin{array}{l}\text { No brain hypoperfusion } \\
(n=31)\end{array}$ & $p$ value \\
\hline \multicolumn{5}{|l|}{ Baseline } \\
\hline $\mathrm{ICP}, \mathrm{mmHg}$ & $13[9-17]$ & 15 [9-19] & $11[8-15]$ & 0.02 \\
\hline $\mathrm{CPP}, \mathrm{mmHg}$ & $94[80-110]$ & $95[81-112]$ & 86 [79-108] & 0.36 \\
\hline $\mathrm{PbtO}_{2}, \mathrm{mmHg}$ & 21 [19-23] & 20 [18-22] & $22[21-25]$ & $<0.01$ \\
\hline $\mathrm{PaO}_{2}, \mathrm{mmHg}$ & 110 [98-124] & 112 [97-127] & 109 [99-122] & 0.79 \\
\hline $\mathrm{FiO}_{2}$ at baseline, $\%$ & $35[30-40]$ & $35[30-40]$ & $30[30-40]$ & 0.04 \\
\hline $\mathrm{PaO}_{2} / \mathrm{FiO}_{2}$ at baseline & 327 [283-365] & 312 [269-357] & 338 [297-370] & 0.10 \\
\hline PEEP, $\mathrm{cmH}_{2} \mathrm{O}$ & $8[5-10]$ & $8[5-10]$ & $8[5-10]$ & 0.68 \\
\hline $\mathrm{pH}$ & $7.42[7.38-7.44]$ & $7.42[7.38-7.44]$ & 7.41 [7.39-7.43] & 0.82 \\
\hline $\mathrm{PaCO}_{2}$ baseline, $\mathrm{mmHg}$ & 39 [36-43] & 39 [37-42] & 38 [35-41] & 0.06 \\
\hline Sodium, mmol/L & 140 [138-144] & 140 [138-144] & 140 [138-142] & 0.59 \\
\hline Hemoglobin, g/dL & $10.3[9.1-11.4]$ & $10.2[9.6-11.6]$ & 10.5 [8.9-11.3] & 0.56 \\
\hline Glucose, mg/dL & 134 [121-145] & 133 [119-144] & 138 [126-154] & 0.20 \\
\hline Body temperature, ${ }^{\circ} \mathrm{C}$ & $37.1[36.8-37.5]$ & $37.2[36.7-37.6]$ & 37.1 [36.9-37.5] & 0.98 \\
\hline Sedatives, n (\%) & $48(55)$ & $31(55)$ & $17(55)$ & 1.00 \\
\hline Opioids, n (\%) & $54(62)$ & $34(61)$ & $20(65)$ & 0.82 \\
\hline NMBAs, n (\%) & $22(25)$ & $14(25)$ & $8(26)$ & 1.00 \\
\hline Norepinephrine, n (\%) & $66(76)$ & $43(77)$ & $23(74)$ & 0.80 \\
\hline Inotropic agents, n (\%) & $20(23)$ & $13(23)$ & $7(23)$ & 1.00 \\
\hline \multicolumn{5}{|c|}{ End of the dynamic oxygen challenge } \\
\hline $\mathrm{PbtO}_{2}, \mathrm{mmHg}$ & 79 [56-95] & $62[46-88]$ & $91[81-119]$ & $<0.01$ \\
\hline $\mathrm{PaO}_{2}, \mathrm{mmHg}$ & 359 [319-410] & 345 [315-407] & 378 [339-418] & 0.08 \\
\hline $\mathrm{pH}$ & $7.42[7.38-7.43]$ & $7.42[7.37-7.44]$ & $7.42[7.39-7.43]$ & 0.74 \\
\hline $\mathrm{PaCO}_{2}, \mathrm{mmHg}$ & $39[36-44]$ & $39[36-44]$ & $38[36-42]$ & 0.72 \\
\hline Oxygen ratio & $0.23[0.15-0.29]$ & $0.21[0.12-0.27]$ & $0.28[0.22-0.33]$ & $<0.01$ \\
\hline $\mathrm{rCBF}, \mathrm{mL} / 100 \mathrm{~g} \times \min$ & $31.3[22.6-41.3]$ & $25.6[15.4-31.2]$ & $49.3[40.4-68.0]$ & $<0.01$ \\
\hline
\end{tabular}

ICP Intracranial pressure, $\mathrm{CPP}$ cerebral perfusion pressure, $\mathrm{PbtO}_{2}$ brain tissue oxygen pressure, $\mathrm{PaO}_{2}$ arterial blood partial pressure of oxygen, $r C B F$ regional cerebral blood flow, NMBA neuromuscular blocking agents

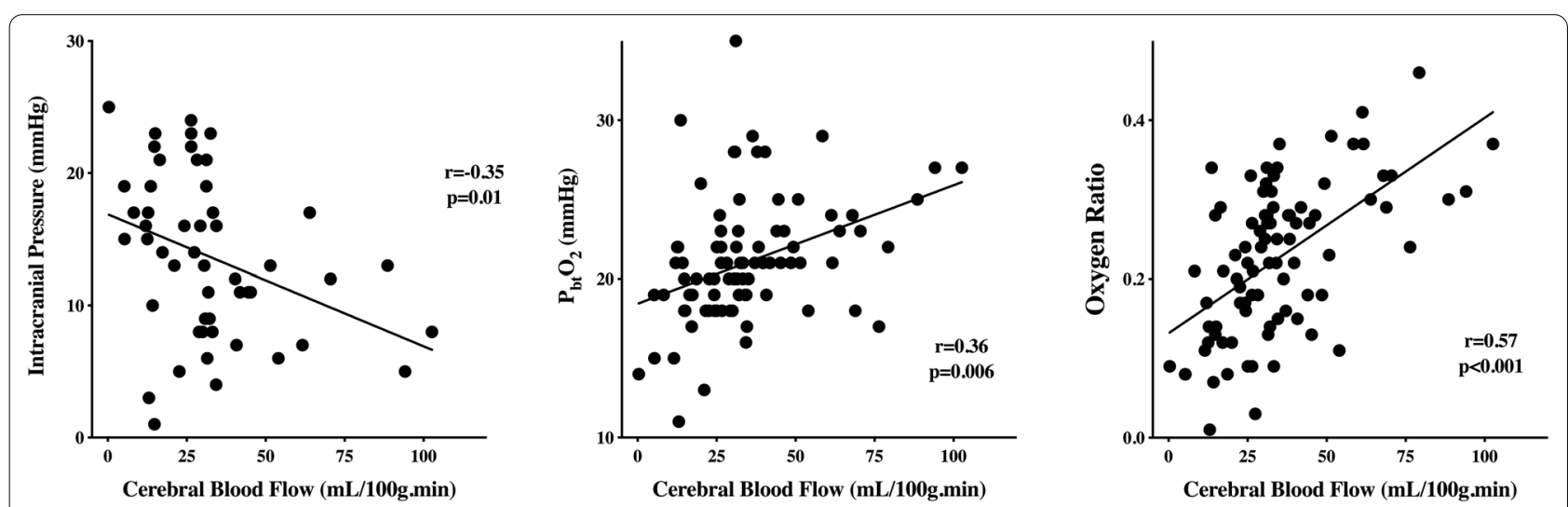

Fig. 3 Correlation between baseline intracranial pressure, baseline brain oxygen pressure $\left(\mathrm{PbtO}_{2}\right)$ and oxygen ratio with regional cerebral blood flow (CBF) 
Table 3 Correlation between regional CBF and monitoring parameters. The discriminative ability of each variable or combination to predict cerebral hypoperfusion (i.e., regional $\mathrm{CBF}<35 \mathrm{~mL} / 100 \mathrm{~g} \times \mathrm{min})$ was evaluated using receiver operating characteristic curves with the corresponding area under the curve (AUROC), and sensitivity, specificity, positive (PPV) and negative predictive value (NPV) were computed

\begin{tabular}{lll}
\hline & Correlation with rCBF & AUROC $(\mathbf{9 5} \% \mathbf{C I})$ \\
\hline $\mathrm{ICP}$ & $r=-0.27 ; p=0.01$ & $0.65(0.53-0.76)$ \\
$\mathrm{PbtO}_{2}$ & $r=0.36 ; p<0.01$ & $0.75(0.64-0.85)$ \\
Oxygen ratio & $r=0.57 ; p<0.01$ & $0.75(0.63-0.85)$ \\
$\mathrm{CPP}$ & $r=0.01 ; p=0.92$ & $0.57(0.44-0.70)$ \\
$\mathrm{ICP}+\mathrm{PbtO}_{2}$ & - & $0.78(0.68-0.87)$ \\
$\mathrm{ICP}+\mathrm{OxR}$ & - & $0.78(0.68-0.88)$ \\
$\mathrm{ICP}+\mathrm{PbO}_{2}+$ oxygen & - & $0.80(0.70-0.91)$ \\
ratio & &
\end{tabular}

ICP intracranial pressure, $C P P$ cerebral perfusion pressure, $\mathrm{PbtO}_{2}$ brain tissue oxygen pressure, $\mathrm{Cl}$ confidence intervals

accuracy of this multimodal approach to detect brain hypoperfusion. Similar results were observed when traumatic and non-traumatic brain injuries were analyzed separately.

The most accurate technique to quantify CBF in critically ill patients is CTP; indeed, assessment of CBF velocities using transcranial Doppler cannot provide absolute values of $\mathrm{CBF}$ [21], while thermodilution techniques are invasive and require repeated calibrations; their use can be limited in patients with fever or when the probe is placed close to large vessels and suffer from progressive drift of measured CBF values, which can result in inappropriate therapeutic decisions [22]. As CTP required patient's transportation (i.e., increased risk of hypotension, hypoxemia, increased ICP) and is associated with not neglectable radiations exposure [12], bedside surrogates of $\mathrm{CBF}$ are necessary to provide continuous and reliable assessment of brain hemodynamics in acute brain-injured patients. Elevated ICP is often used in clinical practice to identify patients at risk of brain hypoperfusion; however, CBF can also be within high ranges after TBI, indicating hyperemia, which would result in a poor correlation of ICP with absolute CBF values [23]. Moreover, brain hypoperfusion can occur also in braininjured patients with ICP values below the cutoff of 20-22 mmHg, which has been commonly used to define "intracranial hypertension", independently from cerebral perfusion pressure (CPP) values [14]. Our data are in line with previous studies that reported a limited accuracy for ICP and CPP to predict CBF values or brain hypoperfusion, while a good correlation between $\mathrm{PbtO}_{2}$ and CBF was observed [24-26]; moreover, we showed that this correlation was present also for non-traumatic brain injuries, such $\mathrm{SAH}$ and $\mathrm{ICH}$. Importantly, the $\mathrm{PbtO}_{2}$ probe was placed into the "at-risk" area (i.e., normal appearing but close to a contusion or injured region), and our results might not be applicable in cases where probe insertion might target different cerebral areas. Moreover, we focused only on the area surrounding the $\mathrm{PbtO}_{2}$ catheter, as we included not only patients with diffuse brain injury (i.e., as it might be the case for TBI patients with diffuse axonal injury), but also many with focal injury (i.e., traumatic contusion or intracerebral hemorrhage), in whom the regional CBF might not correlate adequately with the global CBF of the ipsilateral cerebral hemisphere.

Importantly, median ICP and $\mathrm{PbtO}_{2}$ were within normal values, i.e., clinical scenarios where performing additional measures, including neuroimaging, can be debatable. As such, our findings should be considered as physiological investigations of the relationship between $\mathrm{CBF}$ and neuromonitoring data rather than a support to perform more frequently CTP in this setting.

Previous studies have tried to improve the accuracy of multimodal neuromonitoring to detect brain hypoperfusion by adding, as an example, cerebral microdialysis (i.e., in particular, reduced cerebral glucose or high lactate to pyruvate ratio, which might suggest anaerobic metabolism occurring because of tissue hypoxia) [15]. However, cerebral microdialysis is available only in few centers, and interpretation of its data requires one-hour fluid collection, i.e., it might not be sensitive enough to rapid changes in $\mathrm{CBF}$, which could be detected by monitoring systems providing real-time values. The dynamic hyperoxia test at the bedside could potentially help to improve the accuracy of multimodal neuromonitoring to detect brain hypoperfusion. Indeed, normal $\mathrm{PbtO}_{2}$ might be still associated with brain hypoperfusion in patient treated with permissive hyperoxia (i.e., $\mathrm{PaO}_{2}>150 \mathrm{mmHg}$ ) [27]; in this setting, normal $\mathrm{PbtO}_{2}$ values would not reflect normal CBF values but the high levels of dissolved oxygen at the arterial capillary side, which might increase interstitial oxygen diffusion and global delivery. Moreover, low $\mathrm{PbtO}_{2}$ values could be observed in the presence of normal or high CBF values, in particular in case of reduced arterial oxygen content (i.e., anemia or hypoxemia) or increased cerebral oxygen consumption (i.e., fever, agitation or fever) [16]. In one study, the OxR was weakly but significantly correlated with ICP and CPP in TBI patients [17]; no direct CBF assessment was performed in this population. However, in a subgroup of patients in whom hyperventilation (i.e., inducing a reduction of CBF) was performed, the OxR was significantly reduced by more than $10 \%$, suggesting a potential relationship between the magnitude of $\mathrm{PbtO}_{2}$ response to hyperoxia and the baseline CBF. In another study including 83 TBI patients, the 
OxR was significantly different across different ranges of CBF values, being lower for CBF of $<10$ or $11-15 \mathrm{~mL} / 100$ $\mathrm{g} \times \mathrm{min}$ and higher for CBF $>40 \mathrm{~mL} / 100 \mathrm{~g} \times \mathrm{min}$ ) [28].

Which are the clinical implications of our findings? As the increase in $\mathrm{PbtO}_{2}$ following hyperoxia might be reduced in the presence of low $\mathrm{CBF}$, the OxR might be easily used at the bedside to identify patients at risk of brain hypoperfusion. Although absolute OxR values did not increase the accuracy of ICP and baseline $\mathrm{PbtO}_{2}$ to detect brain hypoperfusion in our cohort, the presence of low OxR values (i.e., <0.2) could identify still some patients with low CBF values despite ICP and $\mathrm{PbtO}_{2}$ within "normal ranges". Conversely, normal OxR in the presence of slightly elevated ICP with still normal $\mathrm{PbtO}_{2}$ might suggest the presence of cerebral hyperemia; also, isolated low $\mathrm{PbtO}_{2}$ with normal OxR might imply an imbalance between oxygen delivery and consumption that is independent from CBF, i.e., low oxygen content or increased oxygen consumption. This might help to further individualize patients' care according to the underlying mechanisms resulting in tissue hypoxia. Importantly, it is important to consider that CTP, especially if used in isolation, had limited diagnostic utility to predicting infarct after ischemic stroke [29]; hence, using one single CTP imaging as the "gold standard" to assess hypoperfusion can be somewhat debatable, and, although being used in other studies [15], will deserve further confirmatory analyses in brain-injured patients.

This study has several limitations to acknowledge. First, the study was single-center and local practices might limit generalizability of the results. Second, we included both traumatic and non-traumatic injuries; although these diseases have a significant heterogeneity in pathophysiology and overall management, main results about OxR were similar in the subgroup analysis. Third, we did not specifically assess whether OxR, on admission or repeatedly measured during the ICU stay, might be associated with patients' outcome, as suggested into another study [17]. Also, we did not evaluate whether fluctuations of ICP and $\mathrm{PbtO}_{2}$ might also provide more clinically relevant information on brain perfusion than baseline ICP/ $\mathrm{PbtO}_{2}$ values or OxR in this setting. Fourth, we did not assess how CBF might respond to hyperoxia; in previous studies, the authors observed a slight decrease in ICP following breathing $\mathrm{FiO}_{2} 100 \%$, which might suggest intact autoregulatory mechanisms, resulting in vasoconstriction in response to elevated oxygen pressure to maintain a constant tissue oxygen delivery [28]. Fifth, the prevalence of brain hypoperfusion in our study was particularly high, reflecting clinical decision of the attending physicians to explore patients at risk of brain hypoperfusion. A prospective study including all brain-injured patients with neuromonitoring, independently on the pretest probability of brain hypoperfusion, could provide a more extensive and reliable assessment of the role of OxR to detect low CBF values in this setting. Sixth, $\mathrm{PbtO}_{2}$ probes were placed in the anterior and middle cerebral artery territories; therefore, changes in posterior vascular territories were not specifically evaluated. Seventh, one may argue that, in the small area where brain oxygenation is measured, CBF would be highly negatively impacted by the instrumented probe. However, regional $\mathrm{CBF}$ varied across a wide ranges of values in our study, i.e., many patients had normal or high $\mathrm{CBF}$ values. If the tip would have been a reason for low CBF, then oligemia would have been observed in all patients. Moreover, the tip was placed in the region "at risk", i.e., the cerebral area suffering from contusion, edema or vasospasm; as such, it was expected to have lower regional CBF in the analyzed region than other normal appearing areas (in particular for TBI and ICH). In a previous study [15], a similar methodological approach was used than in our study; also, the authors showed that regional CBF was correlated (although with same variance) with global CBF. Finally, measurement of absolute CBF might not adequately assess the degree of tissue hypoxia; indeed, CBF values within "normal" ranges might still be insufficient for cerebral areas at high metabolic rates or when low arterial oxygen content is present. However, most of therapeutic strategies aim at increasing brain perfusion in acute brain injured patients, and the assessment of $\mathrm{CBF}$ remains a relevant end-point in this setting.

\section{Conclusions}

In a heterogeneous population of acute brain-injured patients, cerebral multimodal monitoring with ICP and $\mathrm{PbtO}_{2}$ detected regional cerebral hypoperfusion with a higher accuracy than ICP alone. Although the absolute values of OxR, which was derived from a dynamic hyperoxia test, did not significantly increase the accuracy of ICP and $\mathrm{PbtO}_{2}$ to detect brain hypoperfusion, low OxR might be still useful to identify those patients with low CBF values despite ICP and $\mathrm{PbtO}_{2}$ values within normal ranges.

\section{Abbreviations}

ABG: Arterial blood gas; AUROC: Area under the receiving operator curve; CBF: Cerebral blood flow; CPP: Cerebral perfusion pressure; CTP: Perfusion computed tomography; FO: Favorable neurological outcome; GOS: Glasgow Outcome Scale; ICH: Intracranial hemorrhage; ICP: Intracranial pressure; NPV: Negative predictive value; OxR: Oxygen ratio; $\mathrm{PaO}_{2}$ : Arterial oxygen pressure; $\mathrm{PbtO}_{2}$ : Brain tissue oxygen pressure; $\mathrm{PPV}$ : Positive predictive value; $\mathrm{rCBF}$ : Regional cerebral blood flow; SAH: Subarachnoid hemorrhage; SBI: Secondary brain injury; TBI: Traumatic brain injury; UO: Unfavorable neurological outcome. 


\section{Supplementary Information}

The online version contains supplementary material available at https://doi. org/10.1186/s13054-022-03918-0.

Additional file 1: Table S1. Number of cerebral CT perfusion with brain hypoperfusion ( $n=56)$, according to the combination of intracranial hypertension or tissue hypoxia. Table $\mathbf{S 2}$. Differences in main available data on the day of cerebral CT perfusion (CTP), according to the presence of brain hypoperfusion (i.e., regional cerebral blood flow $<35 \mathrm{~mL} / 100 \mathrm{~g} x$ $\mathrm{min}$ ) in traumatic brain injury (TBI) patients. Data are presented as count (\%) or median [IQRs]. Table S3. Differences in main available data on the day of cerebral CT perfusion (CTP), according to the presence of brain hypoperfusion (i.e., regional cerebral blood flow $<35 \mathrm{~mL} / 100 \mathrm{~g} \times \mathrm{min}$ ) in non-traumatic brain injury (i.e., subarachnoid hemorrhage, SAH or intracerebral hemorrhage, ICH) patients. Data are presented as count (\%) or median [IQRs]. Table S4. Correlation between regional CBF and monitoring parameters in CTP associated with traumatic brain injury (TBI; $n=19)$. The discriminative ability of each variable or combination to predict cerebral hypoperfusion (i.e., regional $\mathrm{CBF}<35 \mathrm{~mL} / 100 \mathrm{~g} \times \mathrm{min}$ ) was evaluated using receiver operating characteristic curves with the corresponding area under the curve (AUC), and sensitivity, specificity, positive (PPV) and negative predictive value (NPV) were computed. Table S5. Correlation between regional CBF and monitoring parameters in CTP associated with non-traumatic brain injury $(n=68)$. The discriminative ability of each variable or combination to predict cerebral hypoperfusion (i.e., regional $\mathrm{CBF}<35 \mathrm{~mL} / 100 \mathrm{~g} \times \mathrm{min}$ ) was evaluated using receiver operating characteristic curves with the corresponding area under the curve (AUC), and sensitivity, specificity, positive (PPV) and negative predictive value (NPV) were computed. Figure S1. Flowchart of the study. Figure S2. Proportion of cerebral CT perfusion with brain hypoperfusion $(n=56)$, according to the combination of two parameters among intracranial hypertension $(\mathrm{IH})$, tissue hypoxia (BH) or low/high oxygen ratio (OxR). Figure S3. Proportion of cerebral CT perfusion with brain hypoperfusion, according to the combination of the three parameters, i.e., intracranial hypertension $(\mathrm{IH})$, tissue hypoxia (BH) or low/high oxygen ratio (OxR).

\section{Acknowledgements}

None to declare.

\section{Authors' contributions}

FST, GF and TG designed the study; FST, GF, TG, XC, LP and EB collected the data of included patients; RC, MVM and NS interpreted the CTP imaging; FST, GC, $\mathrm{OH}$ and JC contributed to data interpretation; FST, GF, TG, XC and $\mathrm{OH}$ wrote the manuscript; JC, NS, RC, EB and LP critically revised the manuscript; $L P$ and $E B$ contributed to the statistical analysis. All authors read and approved the manuscript.

\section{Funding}

None.

\section{Availability of data and materials}

The datasets used and/or analyzed during the current study are available from the corresponding author on reasonable request.

\section{Declarations}

Ethics approval and consent to participate

The study protocol was approved by local ethics committees, and informed consent was waived because of the retrospective nature of the study.

\section{Consent for publication}

Not applicable.

\section{Competing interests}

The authors declare that they have no competing interests.

\section{Author details}

${ }^{1}$ Department of Intensive Care, Hospital Erasme, Université Libre de Bruxelles (ULB), Route de Lennik, 808, 1070 Brussels, Belgium. ${ }^{2}$ Département d'Anesthésie et Réanimation Chirurgicale, Centre Hospitalier Universitaire de Brest, Université de Bretagne Occidentale (UBO), Brest, France. ${ }^{3}$ Department of Radiology, Hospital Erasme, Université Libre de Bruxelles (ULB), Brussels, Belgium.

Received: 19 November 2021 Accepted: 29 January 2022

Published online: 07 February 2022

\section{References}

1. Lovelock CE, Rinkel GJE, Rothwell PM. Time trends in outcome of subarachnoid hemorrhage: population-based study and systematic review. Neurology. 2010;74(19):1494-501.

2. Cooper DJ, Nichol AD, Bailey M, Bernard S, Cameron PA, Pili-Floury S, et al. Effect of early sustained prophylactic hypothermia on neurologic outcomes among patients with severe traumatic brain injury: the POLAR randomized clinical trial. JAMA. 2018;320(21):2211.

3. Thornhill S, Teasdale GM, Murray GD, McEwen J, Roy CW, Penny KI. Disability in young people and adults one year after head injury: prospective cohort study. BMJ. 2000;320(7250):1631-5

4. Rovlias A, Kotsou S. The influence of hyperglycemia on neurological outcome in patients with severe head injury. Neurosurgery. 2000;46(2):335-42.

5. Brenner M, Stein DM, Hu PF, Aarabi B, Sheth K, Scalea TM. Traditional systolic blood pressure targets underestimate hypotension-induced secondary brain injury. J Trauma Acute Care Surg. 2012;72(5):1135-9.

6. Lelubre C, Bouzat P, Crippa IA, Taccone FS. Anemia management after acute brain injury. Crit Care. 2016;20(1):152.

7. Chesnut RM, Marshall LF, Klauber MR, Blunt BA, Baldwin N, Eisenberg HM, et al. The role of secondary brain injury in determining outcome from severe head injury. J Trauma Acute Care Surg. 1993;34(2):216-22.

8. Werner C, Engelhard K. Pathophysiology of traumatic brain injury. Br J Anaesth. 2007;99(1):4-9.

9. Vilela P, Rowley HA. Brain ischemia: CT and MRI techniques in acute ischemic stroke. Eur J Radiol. 2017;96:162-72.

10. Wintermark M, Chiolero R, Van Melle G, Revelly JP, Porchet F, Regli L, et al. Cerebral vascular autoregulation assessed by perfusion-CT in severe head trauma patients. J Neuroradiol. 2006:33(1):27-37.

11. Wintermark M, Chioléro R, van Melle G, Revelly JP, Porchet F, Regli L, et al. Relationship between brain perfusion computed tomography variables and cerebral perfusion pressure in severe head trauma patients. Crit Care Med. 2004:32(7):1579-87.

12. Fanara B, Manzon C, Barbot O, Desmettre T, Capellier G. Recommendations for the intra-hospital transport of critically ill patients. Crit Care. 2010;14(3):R87

13. Rohlwink UK, Zwane E, Fieggen AG, Argent AC, le Roux PD, Figaji $A A$. The relationship between intracranial pressure and brain oxygenation in children with severe traumatic brain injury. Neurosurgery. 2012;70(5):1220-30

14. Oddo M, Levine JM, Mackenzie L, Frangos S, Feihl F, Kasner SE, et al. Brain hypoxia is associated with short-term outcome after severe traumatic brain injury independently of intracranial hypertension and low cerebral perfusion pressure. Neurosurgery. 2011;69(5):1037-45.

15. Bouzat P, Marques-Vidal P, Zerlauth JB, Sala N, Suys T, Schoettker P, et al. Accuracy of brain multimodal monitoring to detect cerebral hypoperfusion after traumatic brain injury. Crit Care Med. 2015;43(2):445-52.

16. Nortje J, Gupta AK. The role of tissue oxygen monitoring in patients with acute brain injury. Br J Anaesth. 2006;97(1):95-106.

17. van Santbrink H, vd Brink WA, Steyerberg EW, Carmona Suazo JA, Avezaat CJ, Maas Al. Brain tissue oxygen response in severe traumatic brain injury. Acta Neurochir (Wien). 2003;145(6):429-38.

18. Carney N, Totten AM, O'Reilly C, Ullman JS, Hawryluk GWJ, Bell MJ, et al. Guidelines for the management of severe traumatic brain injury. Neurosurgery. 2017;80(1):6-15.

19. Connolly ES, Rabinstein AA, Carhuapoma JR, Derdeyn CP, Dion J, Higashida RT, et al. Guidelines for the management of aneurysmal subarachnoid hemorrhage: a guideline for healthcare professionals from 
the American Heart Association/American Stroke Association. Stroke. 2012;43(6):1711-37.

20. Morgenstern LB, Hemphill JC, Anderson C, Becker K, Broderick JP, Connolly ES, et al. Guidelines for the management of spontaneous intracerebral hemorrhage: a guideline for healthcare professionals from the American Heart Association/American Stroke Association. Stroke. 2010;41(9):2108-29.

21. Bishop CC, Powell S, Rutt D, Browse NL. Transcranial Doppler measurement of middle cerebral artery blood flow velocity: a validation study. Stroke. 1986;17(5):913-5.

22. Fantini S, Sassaroli A, Tgavalekos KT, Kornbluth J. Cerebral blood flow and autoregulation: current measurement techniques and prospects for noninvasive optical methods. Neurophotonics. 2016;3(3):031411.

23. Uzzell BP, Obrist WD, Dolinskas CA, Langfitt TW. Relationship of acute CBF and ICP findings to neuropsychological outcome in severe head injury. J Neurosurg. 1986;65(5):630-5.

24. Doppenberg EM, Zauner A, Bullock R, et al. Correlations between brain tissue oxygen tension, carbon dioxide tension, $\mathrm{pH}$, and cerebral blood flow: a better way of monitoring the severely injured brain? Surg Neurol. 1998:49:650-4.

25. Valadka $A B$, Hlatky $R$, Furuya $Y$, et al. Brain tissue $\mathrm{PO}_{2}$ : correlation with cerebral blood flow. Acta Neurochir Suppl. 2002;81:299-301.

26. Jaeger M, Soehle M, Schuhmann MU, et al. Correlation of continuously monitored regional cerebral blood flow and brain tissue oxygen. Acta Neurochir (Wien). 2005;147:51-6.

27. Puccio AM, Hoffman LA, Bayir $\mathrm{H}$, et al. Effect of short periods of normobaric hyperoxia on local brain tissue oxygenation and cerebrospinal fluid oxidative stress markers in severe traumatic brain injury. J Neurotrauma. 2009;26(8):1241-9.

28. Hlatky R, Valadka AB, Gopinath SP, Robertson CS. Brain tissue oxygen tension response to induced hyperoxia reduced in hypoperfused brain. J Neurosurg. 2008;108(1):53-8.

29. Ho CY, Hussain S, Alam T, Ahmad I, Wu IC, O'Neill DP. Accuracy of CT cerebral perfusion in predicting infarct in the emergency department: lesion characterization on CT perfusion based on commercially available software. Emerg Radiol. 2013;20(3):203-12.

\section{Publisher's Note}

Springer Nature remains neutral with regard to jurisdictional claims in published maps and institutional affiliations.

Ready to submit your research? Choose BMC and benefit from:

- fast, convenient online submission

- thorough peer review by experienced researchers in your field

- rapid publication on acceptance

- support for research data, including large and complex data types

- gold Open Access which fosters wider collaboration and increased citations

- maximum visibility for your research: over $100 \mathrm{M}$ website views per year

At BMC, research is always in progress.

Learn more biomedcentral.com/submissions 